\title{
Underdiagnosis and prognosis of chronic obstructive pulmonary disease after percutaneous coronary intervention: a prospective study
}

This article was published in the following Dove Press journal:

International Journal of COPD

16 July 2015

Number of times this article has been viewed

Pere Almagro'

Anna Lapuente ${ }^{2}$

Julia Pareja'

Sergi Yun'

Maria Estela Garcia ${ }^{3}$

Ferrán Padilla ${ }^{4}$

Josep LI Heredia ${ }^{2}$

Alex De la Sierra'

Joan B Soriano ${ }^{5}$

'Department of Internal Medicine,

${ }^{2}$ Pneumology Service, Mutua de

Terrassa University Hospital, Terrassa,

Spain; ${ }^{3}$ Medical Department, Menarini

Pharmaceutical, Barcelona, Spain;

${ }^{4}$ Cardiology Service, Mutua de

Terrassa University Hospital, Terrassa,

Spain; Instituto de Investigación

Sanitaria Princesa (IP), Universidad

Autónoma de Madrid, Madrid, Spain
Correspondence: Pere Almagro

Department of Internal Medicine,

Mutua de Terrassa University Hospital,

Plaza Dr Robert nㅇ 5, Terrassa 08226,

Barcelona, Spain

Email19908pam@comb.cat
Background: Retrospective studies based on clinical data and without spirometric confirmation suggest a poorer prognosis of patients with ischemic heart disease (IHD) and chronic obstructive pulmonary disease (COPD) following percutaneous coronary intervention (PCI). The impact of undiagnosed COPD in these patients is unknown. We aimed to evaluate the prognostic impact of COPD - previously or newly diagnosed - in patients with IHD treated with PCI.

Methods: Patients with IHD confirmed by PCI were consecutively included. After PCI they underwent forced spirometry and evaluation for cardiovascular risk factors. All-cause mortality, new cardiovascular events, and their combined endpoint were analyzed.

Results: A total of 133 patients (78\%) male, with a mean (SD) age of 63 (10.12) years were included. Of these, 33 (24.8\%) met the spirometric criteria for COPD, of whom $81.8 \%$ were undiagnosed. IHD patients with COPD were older, had more coronary vessels affected, and a greater history of previous myocardial infarction. Median follow-up was 934 days (interquartile range [25\%-75\%]: 546-1,160). COPD patients had greater mortality $(P=0.008$; hazard ratio [HR]: 8.85; 95\% confidence interval [CI]: 1.76-44.47) and number of cardiovascular events ( $P=0.024$; HR: 1.87 ; 95\% CI: 1.04-3.33), even those without a previous diagnosis of COPD $(P=0.01$; HR: $1.78 ; 95 \%$ CI: 1.12-2.83). These differences remained after adjustment for sex, age, number of coronary vessels affected, and previous myocardial infarction $(P=0.025$; HR: 1.83; 95\% CI: 1.08-3.1).

Conclusion: Prevalence and underdiagnosis of COPD in patients with IHD who undergo PCI are both high. These patients have an independent greater mortality and a higher number of cardiovascular events during follow-up.

Keywords: ischemic heart disease, mortality, myocardial infarction, prognosis

\section{Background}

Ischemic heart disease (IHD) and chronic obstructive pulmonary disease (COPD) are within the top causes of mortality worldwide. ${ }^{1}$ The prevalence of IHD is considered increased in patients with COPD and is one of the most frequent causes of death across the entire spectrum of COPD severity. ${ }^{2}$ Nevertheless, the inverse situation - that is, a greater prevalence of COPD and a worse prognosis in IHD patients - has been less studied.

In the past decade, only retrospective studies have indicated that COPD worsens the prognosis of patients with IHD. For example, Berger et al found greater mortality in patients with a previous diagnosis of COPD and IHD who underwent percutaneous coronary intervention (PCI); ${ }^{3}$ these data were corroborated in subsequent studies. ${ }^{4,5}$ Prior diagnosis of COPD has also been related to a greater number of complications and increased mortality in patients with acute myocardial infarction. ${ }^{6-12}$ 
As mentioned, all these studies were retrospective and the diagnosis of COPD was based on clinical history only, without spirometric confirmation, which likely led to an evident underdiagnosis; this explains in part why the prevalence of COPD in these studies is often less than that found in the general population..$^{13,14}$

To our knowledge only one previous study - based in 119 patients - has examined the real prevalence of COPD in patients with IHD as demonstrated with PCI by means of spirometry, revealing a COPD prevalence of $34 \%$, of which $87 \%$ were not previously diagnosed. ${ }^{15}$

We aimed to evaluate whether patients with IHD, demonstrated by PCI, along with COPD confirmed by spirometry with or without previous diagnosis - had a worse prognosis in terms of mortality and increased number of cardiovascular events than patients with IHD alone.

\section{Methods}

All patients admitted at the hemodynamic unit of the Mutua de Terrassa University Hospital due to IHD who underwent a PCI revealing stenosis above $50 \%$ in primary arteries, from January to June 2011, and gave their informed consent, were included. Patients with significant valvulopathy, persistent signs of heart failure, unable to carry out spirometry, and those diagnosed with asthma or bronchiectasis as the main respiratory disease were excluded. Data collected included the characteristics of the PCI, number of arteries affected and treated, stents implanted, and postprocedural flow. At the time of the PCI, the logistic EuroSCORE was calculated, the prognostic evaluation according to the GRACE scale was also recorded and the SYNTAX and ACA/AHA (American College of Cardiology/American Heart Association) coronary lesion complexity indices were analyzed. ${ }^{16-21}$ Analytical variables were drawn at the time of the PCI.

One month after PCI, a postbronchodilator spirometry was performed according to international guidelines, and reviewed by an experienced pulmonologist (JLLH) ${ }^{22} \mathrm{We}$ used a standardized questionnaire to assess the previous diagnosis of COPD ${ }^{15,23}$ Other cardiovascular and COPD risk factors alongside other comorbidities, both included or not in the Charlson index, were recorded. ${ }^{24}$ COPD was defined as a post-bronchodilator forced expiratory volume in the 1 st second $\left(\mathrm{FEV}_{1}\right)$ /forced vital capacity $(\mathrm{FVC})$ ratio $<0.70$. Spirometric severity was stratified in accordance with the Global initiative for chronic Obstructive Lung Disease (GOLD) normative..$^{25}$ The lower limit of normality (LLN) was also calculated, using the Global Lung Function Initiative software (http://www.lungfunction.org). The patients' regular physicians were informed of their spirometric data, without posterior intervention on the part of the researchers in their medication or additional tests performed on the patients. Follow-up was carried out based upon the information contained in the clinical record and by means of telephone contact. Data and cause of death were collected, as was information on admissions for cardiovascular or respiratory reasons. A combined mortality/ major cardiovascular event (MACE) variable including death or hospital admission for a new acute coronary syndrome, heart failure, or cerebral vascular event, was calculated. A study based on the number of MACE events was also performed. The relationship between predicted $\mathrm{FEV}_{1} \%$, predicted $\mathrm{FVC} \%$, and $\mathrm{FEV}_{1} / \mathrm{FVC}$, expressed as a continuous variable stratified for events, was also examined.

\section{Statistical analysis}

Data are presented as means and standard deviation (SD) for continuous variables, or as totals and percentages for qualitative variables. Differences within groups were compared with Student's $t$-test or non-parametric tests and the chi-squared test for continuous and categorical variables, respectively. Time-dependent variables were analyzed with Kaplan-Meier curves and Cox logistic regression analysis. Statistical significance was determined for $P$-values below 0.05 . All patients signed their informed consent. The study was approved by the ethical and clinical trial committee of the Mutua de Terrassa University Hospital.

\section{Results}

A total of 171 patients were initially studied, of whom 38 were then excluded. Excluded patients were older: 63 (10.12) vs 67.64 (12.42) years $(P=0.022)$, although there were no differences in terms of sex, history of cardiovascular risk, or number of treated arteries. Finally, 133 patients were included (78.2\% males) with a global mean (SD) age of 63.03 (10.12) years and $33(24.8 \%)$ met the spirometric criteria for COPD. Ten patients had mild COPD (30.3\%), 19 moderate COPD (57.6\%), and four severe COPD (12.1\%). The global prevalence of underdiagnosis was $81.8 \%$. All of the severe COPD patients had been previously diagnosed, while underdiagnosis in patients with moderate and mild COPD was $89.5 \%$ and $100 \%$, respectively (Figure 1).

The main characteristics of the participants in the presence or not of COPD are presented in Table 1. Patients with COPD were significantly older and had a more frequently history of previous myocardial infarction, while the Charlson index was similar between groups. Previous use of antiplatelets and statins, and other indicators of cardiovascular risk, was not significantly 


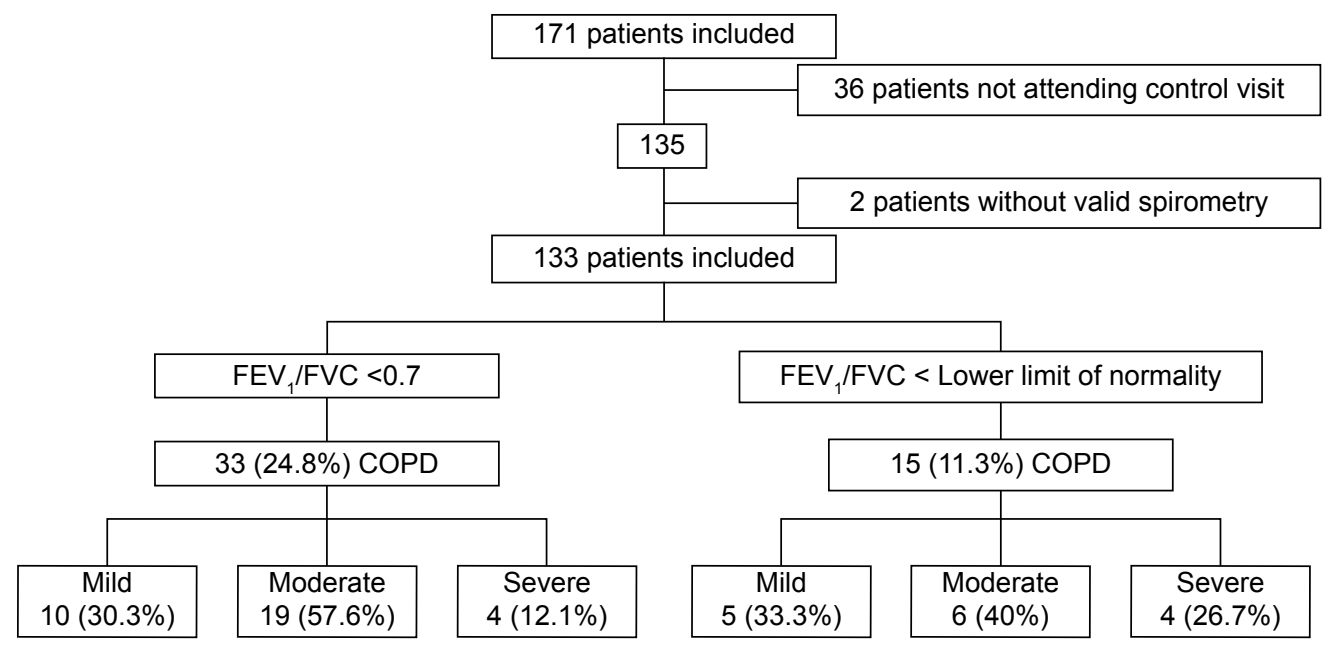

Figure I Flowchart of patients.

Abbreviations: COPD, chronic obstructive pulmonary disease; $F E V_{1}$, forced expiratory volume in the Ist second; FVC, forced vital capacity.

different. Findings obtained in the PCI are shown in Table 2. COPD patients had a greater number of affected coronary arteries, although there were no differences in the number of arteries or lesions treated, the percentage of patients achieving total revascularization, the number of stents implanted - drugeluting or otherwise - or the ejection fraction (Table 2).

In accordance with the ACC/AHA classification, 7\% had type a lesions, $60 \%$ type $\mathrm{b}$, and $33 \%$ type $\mathrm{c}$, with no difference between the COPD patients and the rest; similarly scoring was similar for those with and those without COPD on the Syntax index in grouping those at low risk (0-22), medium risk (23-32), and high risk ( $\geq 33)$.

Analytic parameters were likewise comparable. Those patients with COPD had lower total cholesterol levels although this difference disappeared when subjects with a prior diagnosis of dyslipidemia or under treatment with statins were analyzed (Table 3). We did not find differences between patients with and without COPD at the time of discharge after

Table I Demographic and clinical characteristics of participants according to spirometry FEV /FVC $<0.70$

\begin{tabular}{|c|c|c|c|c|}
\hline & COPD (n=33) & Non-COPD $(n=\mid 00)$ & Total $(n=133)$ & $P$-value \\
\hline Male sex (n) (\%) & $28(84.8)$ & $76(76)$ & $78.2 \%$ & ns \\
\hline Age, years (SD) & 67.48 (9.91) & 61.56 (9.79) & $63.03(10.1)$ & 0.003 \\
\hline BMI $\left(\mathrm{kg} / \mathrm{m}^{2}\right)$ & 28.91 (5.43) & 31.3 (I4.74) & 30.71 (13.0I) & ns \\
\hline Smoking & & & & ns \\
\hline Current & $6(18.2 \%)$ & $17(17 \%)$ & $23(17.3 \%)$ & \\
\hline Ex-smoker & $21(63.65 \%)$ & $57(57 \%)$ & $78(58.6 \%)$ & \\
\hline Pack-years & $35.23(20.63)$ & $27.79(25.62)$ & $29.82(24.5)$ & ns \\
\hline Charlson's index & $1.87(1.49)$ & $1.48(1.26)$ & $1.57(1.32)$ & ns \\
\hline Waist circumference & 100.77 (10.57) & $103.7 \mid(9.68)$ & $103(9.94)$ & ns \\
\hline Dyslipidemia $^{a}$ & $22(66.7 \%)$ & $62(62 \%)$ & $84(63.2 \%)$ & ns \\
\hline Peripheral vasculopathy ${ }^{a}$ & $3(9.1 \%)$ & $5(5 \%)$ & $8(6 \%)$ & ns \\
\hline Hypertension ${ }^{\mathrm{a}}$ & $23(69.7 \%)$ & $100(69 \%)$ & $92(69.2 \%)$ & ns \\
\hline Diabetes mellitus ${ }^{\mathrm{a}}$ & $12(36.4 \%)$ & $27(27 \%)$ & $39(29.3 \%)$ & ns \\
\hline Heart failure $^{\mathrm{a}}$ & $6(18.2 \%)$ & $9(9 \%)$ & $15(11.3)$ & ns \\
\hline Stroke ${ }^{a}$ & $3(9.1 \%)$ & $3(3 \%)$ & $6(4.5 \%)$ & ns \\
\hline $\mathrm{AMI}^{\mathrm{a}}$ & $14(42.4 \%)$ & $24(24 \%)$ & $38(28.6 \%)$ & 0.03 \\
\hline Angina $^{\mathrm{a}}$ & $22(66.7 \%)$ & $54(54 \%)$ & $76(57.1 \%)$ & ns \\
\hline Cardiac surgery & $8(24.2 \%)$ & $21(21 \%)$ & $29(21.8 \%)$ & ns \\
\hline Previous use statins & $17(5 \mid .5 \%)$ & $65(65 \%)$ & $82(61.7 \%)$ & ns \\
\hline Previous use antiplatelets & $18(54.5 \%)$ & $60(60 \%)$ & $78(58.6 \%)$ & ns \\
\hline Depression: Yesavage scale, mean (SD) & $3.82(2.82)$ & $4.05(3.8)$ & $3.99(3.56)$ & ns \\
\hline
\end{tabular}

Notes: aPrevious diagnosis of dyslipidemia, arterial peripheral vasculopathy, diabetes mellitus, hypertension, heart failure, stroke, acute myocardial infarction (AMI), angina or cardiac surgery.

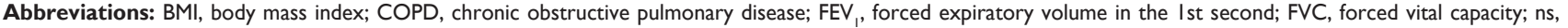
non-significant; SD, standard deviation. 
Table 2 Characteristics of the $\mathrm{PCl}$, according to spirometry $\mathrm{FEV}_{1} / \mathrm{FVC}<0.70$

\begin{tabular}{|c|c|c|c|c|}
\hline & COPD $(n=33)$ & Non-COPD $(n=100)$ & Total $(n=133)$ & $P$-value \\
\hline GRACE score at hospital (SD) ${ }^{18}$ & $16.36(26.96)$ & $10.23(5.44)$ & 14.4 & ns \\
\hline GRACE score at 6 months (SD) ${ }^{18}$ & $25.21(2|| 8)$. & $19.8(8.43)$ & $21.20(12.96)$ & ns \\
\hline Logistical EuroSCORE (median and IQR) ${ }^{17}$ & $11(6-15)$ & $2(2-3.8)$ & $3(2-10)$ & 0.006 \\
\hline SYNTAX (SD) ${ }^{19}$ & $13.77(10.81)$ & $13.09(10.42)$ & $13.25(10.46)$ & ns \\
\hline Number of arteries affected (SD) & I.91 (0.84) & $\mathrm{I} .56(0.7)$ & $\mathrm{I} .64(0.75)$ & 0.04 \\
\hline Number of arteries treated (SD) & $1.3(0.47)$ & $1.23(0.48)$ & $1.25(0.47)$ & ns \\
\hline Number of lesions treated (SD) & $\mathrm{I} .47(0.67)$ & $\mathrm{I} .44(0.69)$ & $\mathrm{I} .45(0.68)$ & ns \\
\hline Number of stents (SD) & $\mathrm{I} .47(0.69)$ & $1.4(0.66)$ & $\mathrm{I} .42(0.67)$ & ns \\
\hline Number of drug-eluting stents (SD) & $1.21(0.92)$ & $0.96(0.89)$ & I.0I (0.89) & ns \\
\hline Ejection fraction (SD) & $56.67(13.26)$ & $60.20(13.31)$ & $59.26(13.32)$ & ns \\
\hline Complete revascularization (\%) & $10(30.3 \%)$ & $46(46 \%)$ & $56(42.1 \%)$ & ns \\
\hline
\end{tabular}

Abbreviations: COPD, chronic obstructive pulmonary disease; FEV , forced expiratory volume in the Ist second; FVC, forced vital capacity; IQR, interquartile range (25\%-75\%); PCl, percutaneous coronary intervention; SD, standard deviation.

PCI or during follow-up in the prescription of antiplatelets, statins, beta-blockers, angiotensin-converting-enzyme (ACE) inhibitors, angiotensin II inhibitors, or calcium antagonists (Figure 2). There were, however, differences in the use of bronchodilators and inhaled corticosteroids, both more frequent among the patients with COPD $(P<0.001)$.

The median follow-up period was 974 (interquartile range: 546-1,160) days. During follow-up eight deaths occurred, six in the COPD group (18.2\%) and two in the nonCOPD group ( $2 \%)(P=0.003)$. There were 88 new events, of which 35 were in the COPD group and 53 in the non-COPD group $(P=0.015)$, as well as a greater number of events per patient: $1.36(0.29)$ vs $0.63(0.97)(P=0.02)$.

When analyzing survival and MACE using a Cox regression model, COPD patients showed a worse prognosis with regard to mortality $(P=0.008$; hazard ratio [HR]: 8.85; 95\% confidence interval [CI]: $1.76-44.47)$ and to the MACE variable ( $P=0.024$; HR: 1.87 ; 95\% CI: $1.04-3.33$ ). These differences were sustained when the total number of events in the MACE variable was examined in relation to whether or not the patient had COPD $(P=0.003$; HR: 1.84; 95\% CI: 1.14-2.74) (Figure 3). COPD patients without a prior diagnosis also showed a worse prognosis with the MACE variable $(P=0.001$; HR: $1.78 ; 95 \% \mathrm{CI}: 1.12-2.83)$ (Figure 4A). The significance of COPD was maintained after adjusting for age, sex, previous myocardial infarction, and number of arteries affected (Table 4 and Figure 5).

When classifying the COPD patients in terms of LLN the prevalence observed went down to 15 patients $(11.3 \%)$, five with mild COPD, six with moderate, and four with severe, thereby reducing the underdiagnosis to $67 \%$. In terms of LLN, no differences in mortality were found, although statistical significance was maintained for the MACE variable ( $P=0.03$; HR: 2.26 ; 95\% CI: $1.1-4.68)$ and for the total number of events in the non-adjusted analysis ( $P=0.002$; HR: 2.37 ; 95\% CI: $1.48-3.83)$. However, this significance disappeared in the multivariate model (Table 4 and Figure 5). The number of arteries with stenosis maintained its statistical significance in both multivariate models.

Subjects with discordant results (obstructive by fixed ratio but normal by LLN) had a greater number of events than patients without COPD and a smaller number than the patients meeting both criteria $(P<0.002)$. Total number

Table 3 Blood analysis of participants according to spirometry FEV,/FVC $<0.70$

\begin{tabular}{|c|c|c|c|c|}
\hline & COPD $(n=33)$ & Non-COPD $(n=100)$ & Total $(n=133)$ & $P$-value \\
\hline Total cholesterol $(\mathrm{mg} / \mathrm{dL})$ & $161.33(46.29)$ & $182.86(42.92)$ & I77.24 (44.64) & 0.02 \\
\hline HDL cholesterol (mg/dL) & $45.46(12.97)$ & 45.98 (II.98) & $45.85(12.182)$ & ns \\
\hline LDL cholesterol (mg/dL) & 90 (32.59) & $106.35(39.78)$ & $102.4 \mid(38.66)$ & ns \\
\hline Triglycerides (mg/dL) & $105.69(92.46)$ & I34.29 (73.26) & $127.02(79.14)$ & ns \\
\hline CRP & $2(5.45)$ & $0.87(2.1)$ & $1.13(3.21)$ & ns \\
\hline BNP (pg/mL) & I,839 $(4,137)$ & $832(2,437)$ & $1,092(2,984)$ & ns \\
\hline Total cholesterol ${ }^{\mathrm{a}}(\mathrm{mg} / \mathrm{dL})$ & I 67 (40.37) & I8I (43.95) & $177(43.2)$ & ns \\
\hline $\mathrm{HDL}_{\text {cholesterol }}{ }^{\mathrm{a}}(\mathrm{mg} / \mathrm{dL})$ & $46.24(11.25)$ & 44.68 (II.65) & $45.1(11.5)$ & ns \\
\hline LDL cholesterola (mg/dL) & $96.82(31.8)$ & $102.9(4 \mid .2)$ & $101.49(38.99)$ & ns \\
\hline
\end{tabular}

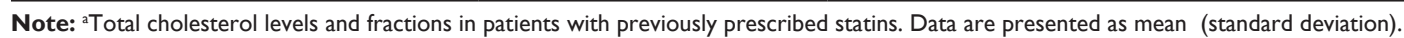

Abbreviations: COPD, chronic obstructive pulmonary disease; FEV ${ }_{1}$, forced expiratory volume in the Ist second; FVC, forced vital capacity. BNP, brain natriuretic peptide; CRP, c-reactive protein; HDL, high density lipoprotein; LDL, low density lipoprotein; ns, non-significant. 

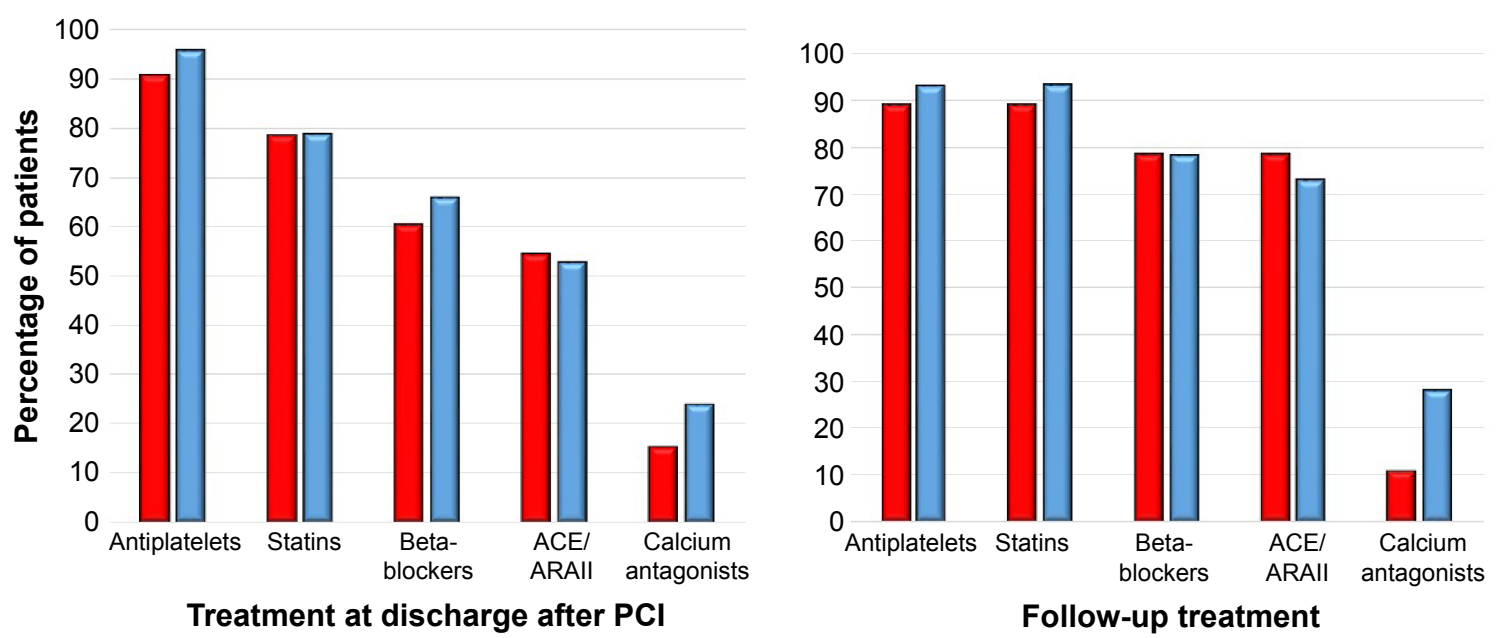

COPD $\square$ Non-COPD

Figure 2 Treatment at discharge and during patient follow-up.

Abbreviations: ACE, angiotensin converting enzyme inhibitors; ARAll, angiotensin II receptor antagonist; COPD, chronic obstructive pulmonary disease; PCl, percutaneous coronary intervention.

of events with Cox regression in the discordant patients were similar to those with the COPD according to the fixed ratio.

The relationship within percent predicted $\mathrm{FVC}, \mathrm{FEV}_{1}$, and $\mathrm{FEV}_{1} / \mathrm{FVC}$ with the number of stratified events was a statistically significant inverse one (Figure 6). Finally when using both the fixed ratio and the lower limit for normality in defining obstruction, the number of events increased with the severity of COPD (both $P<0.0001$ ) (Figure 4B).

\section{Discussion}

Our study demonstrates high rates of prevalence $(25 \%)$ and underdiagnosis $(82 \%)$ of COPD in patients with IHD leading to PCI, as well as lower survival and a greater number of cardiovascular events in patients with COPD, including those who were not previously diagnosed. To our

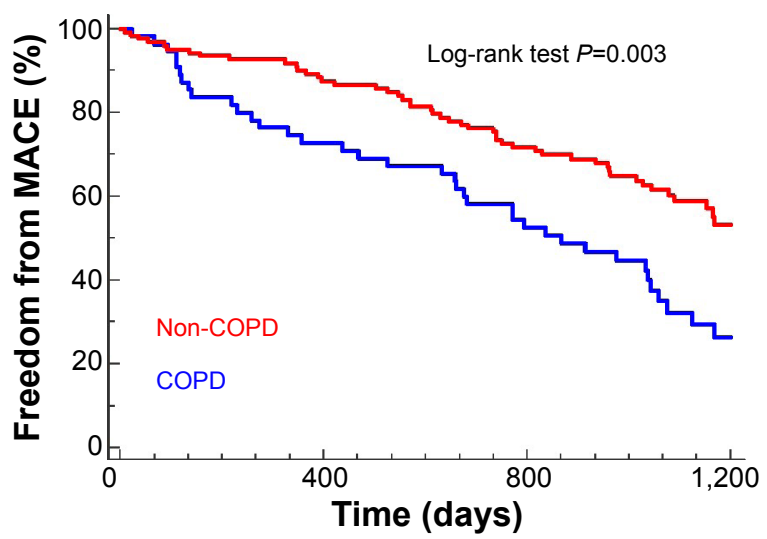

Figure 3 Kaplan-Meier survival curves for the mortality/major cardiovascular event variable (MACE).

Abbreviation: COPD, chronic obstructive pulmonary disease. knowledge, this is the first study in which this prognostic relationship has been demonstrated conjointly using the two techniques considered as GOLD standards: PCI in IHD and spirometry in COPD.

It is well established that COPD is associated with IHD even after adjustment for confounding variables, and that the presence of IHD worsens the prognosis in COPD. ${ }^{26-30}$ The inverse situation - an increase in the risk of COPD in patients with a history of cardiovascular disease - has been shown in other studies. ${ }^{14,31,32}$ The worsened prognosis for patients with IHD and COPD together has been demonstrated in various studies carried out in patients with IHD who have undergone PCI. ${ }^{3-5,9,11,12}$ Other studies have shown a worse prognosis for patients with COPD and acute myocardial infarction, revealing greater risk of heart failure, bleeding, cardiogenic shock, and mortality. ${ }^{6-8,10}$ Unfortunately, none of these studies included a systematic use of spirometry to confirm or rule out the diagnosis of COPD. Rather, they were based solely on a prior diagnosis of COPD in the patient's clinical record or the previous use of bronchodilators, which likely produced a bias and an evident underdiagnosis. Recent studies have shown that, although the specificity of the prior diagnosis of COPD in patients with IHD is high, previous diagnosis sensitivity is very low $(23 \%)$, with a positive predictive value of $53 \% .{ }^{33}$ In our study, the prevalence of underdiagnosis was similar to what was seen in a previous study. ${ }^{15}$

Our data demonstrate that both mortality and the number of events of patients with COPD - with or without previous diagnosis - and concomitant IHD were greater than in IHD patients without COPD. COPD patients were similar to the others except for their more advanced age, a higher number 


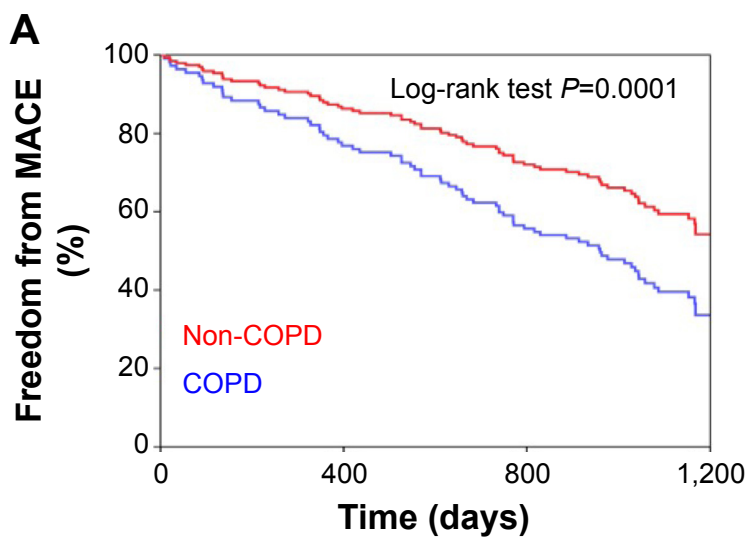

Patients without prior COPD diagnosis

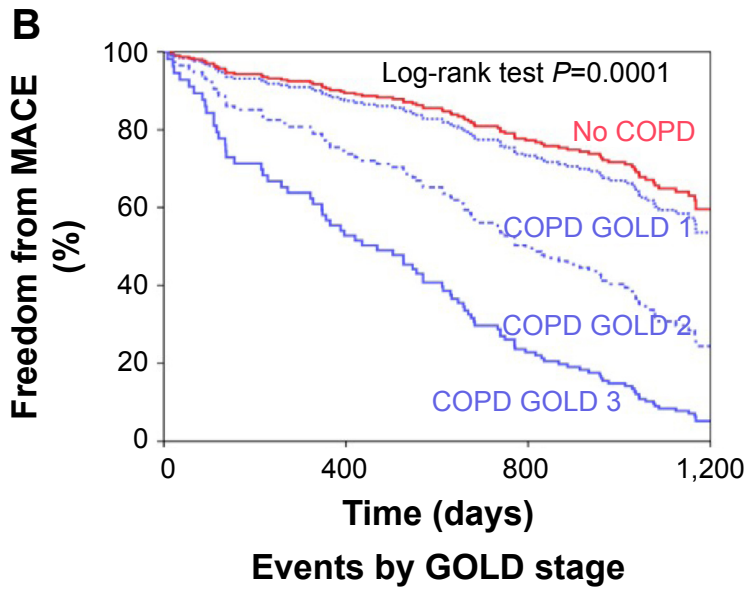

Figure 4 Kaplan-Meier curves for (A) Patients without prior diagnosis of COPD. (B) Total number of events by GOLD stage. Abbreviations: COPD, chronic obstructive pulmonary disease; GOLD, Global initiative for chronic Obstructive Lung Disease; MACE, mortality/major cardiovascular event variable.

of previous incidents of infarction, and a greater number of stenosed arteries. Several previous retrospective studies have also found a greater prevalence of prior infarction in patients with COPD, although data concerning the number of stenosed arteries, the complexity of the coronary lesions, and the procedures for revascularization in these studies were variable. ${ }^{3-5,9,11}$ Nevertheless, the rest of the parameters analyzed in our study, including the GRACE risk and the Syntax and ACC/AHA coronary complexity scales, were similar. Only the logistic EuroSCORE was higher in COPD patients, although this difference may be explained by the older age and prior diagnosis of COPD in some patients, variables that are included in this index.

The number of arteries with stenosis was related to a higher number of events during follow-up, in both the crude and the adjusted analysis, which is in agreement with other studies ${ }^{34}$ However, the number of arteries treated and the

Table 4 Multivariate analysis by event using Cox regression

\begin{tabular}{llll}
\hline & HR & $\mathbf{9 5 \%} \mathbf{C l}$ & P-value \\
\hline COPD fixed ratio & & & \\
COPD & 1.83 & $1.08-3.1$ & 0.025 \\
Sex & 1.1 & $0.62-1.99$ & $\mathrm{~ns}$ \\
Age & 1.01 & $0.98-1.03$ & $\mathrm{~ns}$ \\
AMl & 1.16 & $0.68-1.98$ & $\mathrm{~ns}$ \\
$\quad$ Number of stenosed arteries & 1.45 & $1.08-3.11$ & 0.03 \\
COPD lower limit of normality & & & \\
COPD & 1.47 & $0.77-2.81$ & $\mathrm{~ns}$ \\
Sex & 1.18 & $0.66-2.13$ & $\mathrm{~ns}$ \\
Age & 1.01 & $0.99-1.04$ & $\mathrm{~ns}$ \\
AMl & 1.27 & $0.74-2.18$ & $\mathrm{~ns}$ \\
Number of stenosed arteries & 1.45 & $1.01-2.1$ & 0.046 \\
\hline
\end{tabular}

Note: ${ }^{\text {H}}$ History of previous acute myocardial infarction (AMI).

Abbreviations: AMI, acute myocardial infarction; $\mathrm{Cl}$, confidence interval; COPD, chronic obstructive pulmonary disease; HR, hazard ratio; ns, non-significant. number of stents implanted were somewhat greater in those patients with COPD, albeit short of statistical significance, which suggests that the worse prognosis of COPD patients is not attributable to lessened treatment during the PCI of other arteries with stenosis not responsible for the current coronary event. Recent studies have shown that non-treatment of these arteries is associated with a poor prognosis during follow-up. ${ }^{35}$

The causes of this worse prognosis for patients with IHD and COPD are not entirely clear. Some population-based studies have pointed to poorer adherence to treatment guidelines for IHD in patients with COPD, with less use of statins and beta-blockers, but this was not confirmed in our study, in which the treatment at discharge following PCI and the follow-up with statins, antiplatelets, beta-blockers, calcium antagonists, and ACE inhibitors were comparable. ${ }^{36,37}$ Other possible explanations might include a greater arterial stiffness and higher platelet aggregation and inflammation, all of which are aggravated during COPD exacerbations, with an increased incidence of cardiovascular events in the following weeks after COPD exacerbation..$^{29,38-41}$ This increase in platelet aggregation in COPD patients has also been demonstrated in patients with IHD leading to PCI. ${ }^{42}$

Finally, in our study the use of LLN reduced the level of underdiagnosis but also excluded a sub-group of patients with a greater number of cardiovascular events and their relationship with the number of events in the multivariate model was not significant. These data had already been suggested by other studies that demonstrated an increase in the mortality due to IHD with the reduction of pulmonary function, and higher mortality in those patients classified as non-COPD by LLN but with obstruction criteria from the fixed ratio. ${ }^{43,44}$ 


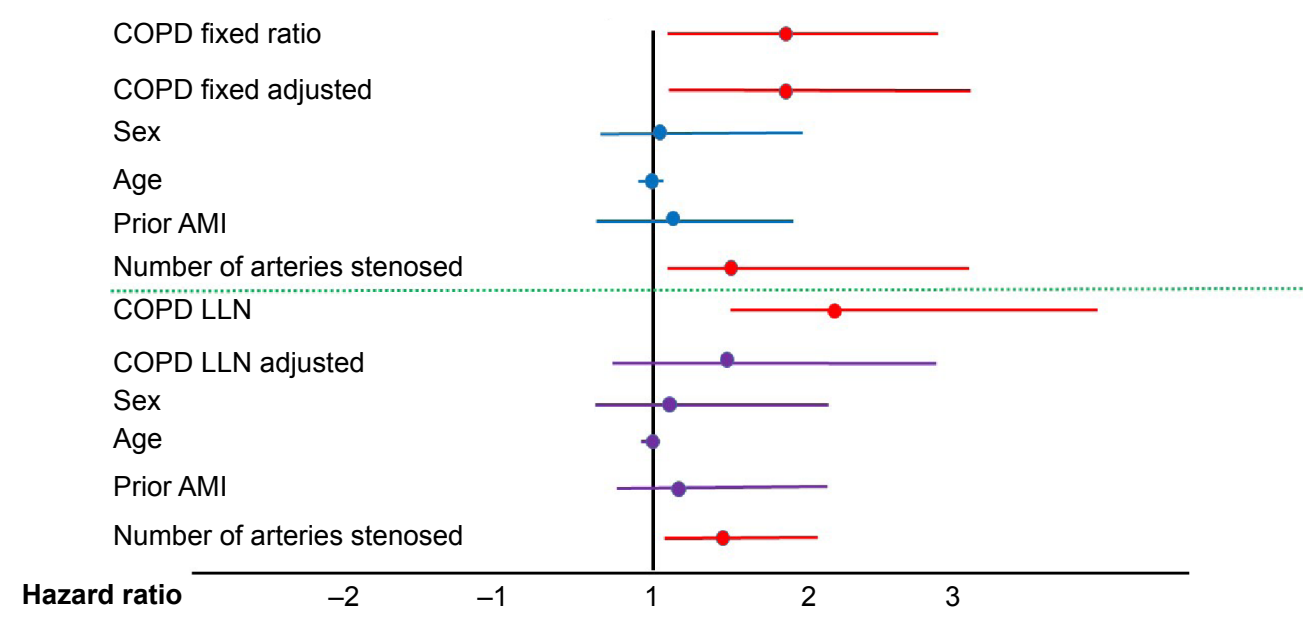

Figure 5 Hazard ratio and $95 \% \mathrm{Cl}$ for COPD by the fixed ratio and the LLN index both raw and adjusted by sex, age, number of arteries with stenosis, and history of AMI. Abbreviations: AMI, acute myocardial infarction; COPD, chronic obstructive pulmonary disease; LLN, lower limit of normality; Cl, confidence interval.

Our study has some limitations. Only IHD patients who underwent PCI were included, so that our conclusions may not be generalized to all patients with IHD; in all likelihood, the oldest patients and those with the most comorbidities were not included as they were not referred for PCI. Although the average age observed in our study was similar to the age in the other studies carried out among PCI patients, it is lower than the overall age for patients with IHD. ${ }^{5,11,45}$ Secondly, by being a single center study we maximize internal consistency in procedures and treatments, but the limited size of the sample may mean that some of the differences observed in the characteristics of patients failed to reach statistical significance. Finally, some classic studies have suggested that myocardial infarction may transiently affect respiratory function, although the $\mathrm{FEV}_{1} / \mathrm{FVC}$ is usually less affected. ${ }^{46}$ In our study, spirometry was performed 1 month after the PCI and recent publications demonstrate that after an acute coronary syndrome treated with PCI, spirometric values performed at this time are similar to those observed during follow-up. ${ }^{47}$

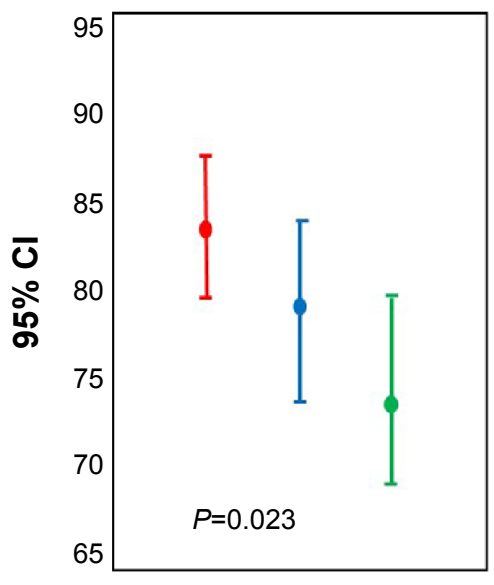

FVC\%

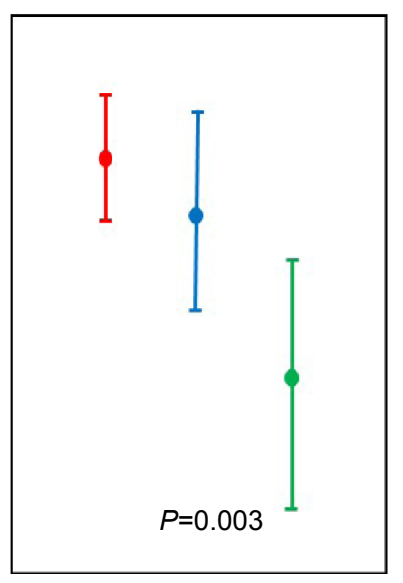

FEV $_{1} \%$

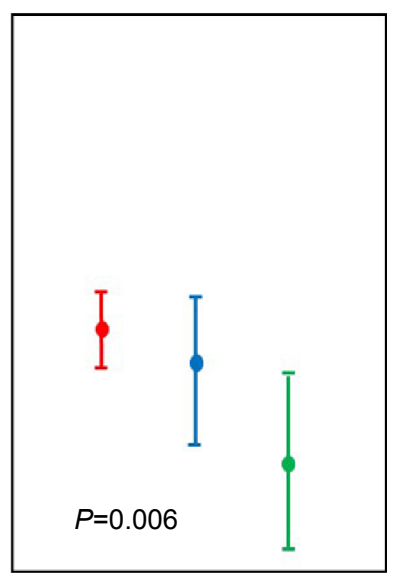

FEV $_{1} /$ FVC

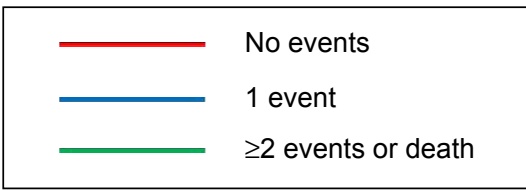

Figure 6 Relationship between number of events (MACE) and percent predicted FVC, FEV , and FEV /FVC.

Abbreviations: $\mathrm{Cl}$, confidence interval; MACE, combined mortality/major cardiovascular event; $\mathrm{FEV}_{1}$, forced expiratory volume in the Ist second; FVC, forced vital capacity. 


\section{Conclusion}

Despite these limitations, we believe that our study demonstrates the poorer prognosis of patients with COPD - with or without previous diagnosis - both in terms of mortality and in cardiovascular events during follow-up independently of other variables, which highlights the need to carry out spirometric studies in order to detect COPD in IHD patients for their prognostic and possibly therapeutic implications. ${ }^{48}$

\section{Acknowledgments}

The CATEPOC study was supported in part by Menarini Spain. The sponsor had no role in the design of the study, the collection and analysis of the data, or the preparation of the manuscript. The authors thank Tom Yohannan who provided medical writing services.

\section{Author contributions}

Conception and design: PA, AL, JP, FP, JLH, AD, JBS; Analysis and interpretation: PA, AL, JP, SY, MEG, FP, JLH, AD, JBS; Drafting the manuscript for important intellectual concept: PA, AL, JP, SY, MEG, FP, JLH, AD, JBS. PA had full access to all of the data in the study and takes responsibility for the integrity of the data and the accuracy of the data analysis.

\section{Disclosure}

The authors report no conflicts of interest in this work.

\section{References}

1. GBD 2013 Mortality and Causes of Death Collaborators. Global, regional, and national age-sex specific all-cause and cause-specific mortality for 240 causes of death, 1990-2013: a systematic analysis for the Global Burden of Disease Study 2013. Lancet. 2015;385(9963):117-171.

2. Soriano JB, Almagro P, Sauleda Roig J. Causes of mortality in COPD. Arch Bronconeumol. 2009;45(Suppl 4):8-13.

3. Berger JS, Sanborn TA, Sherman W, et al. Effect COPD on survival of patients with coronary heart disease having percutaneous coronary intervention. Am J Cardiol. 2004;94(5):649-651.

4. Selvaraj CL, Gurm HS, Gupta R, et al. COPD as a predictor of mortality in patients undergoing percutaneous coronary intervention. Am J Cardiol. 2005;96(6):756-759.

5. Enriquez JR, Parikh SV, Selzer F, et al. Increased adverse events after percutaneous coronary intervention in patients with COPD: insights from the National Heart, Lung and Blood Institute dynamic registry. Chest. 2011;140(3):604-610.

6. Hawkins NM, Huang Z, Pieper KS, et al. COPD is an independent predictor of death but not atherosclerotic events in patients with myocardial infarction: analysis of the Valsartan in Acute Myocardial Infarction Trial (VALIANT). Eur J Heart Fail. 2009;11(3):292-298.

7. Hadi HA, Zubaid M, Al Mahmeed W, et al. Prevalence and prognosis of COPD among 8167 Middle Eastern patients with acute coronary syndrome. Clin Cardiol. 2010;33(4):228-235.

8. Wakabayashi K, Gonzalez MA, Delhaye C, et al. Impact of COPD on acute-phase outcome of myocardial infarction. Am J Cardiol. 2010; 106(3):305-309.
9. Campo G, Guastaroba P, Marzocchi A, et al. Impact of COPD on long-term outcome after ST-segment elevation myocardial infarction receiving primary percutaneous coronary intervention. Chest. 2013; 144(3):750-757.

10. Bursi F, Vassallo R, Weston SA, Killian JM, Roger VL. COPD after myocardial infarction in the community. Am Heart J. 2010;160(1): 95-101.

11. Konecny T, Somers K, Orban M, et al. Interactions between COPD and outcomes after percutaneous coronary intervention. Chest. 2010; 138(3):621-627.

12. Zhang JW, Zhou YJ, Yang Q, Yang SW, Nie B, Xu XH. Impact of COPD on outcomes and hospital days after percutaneous coronary intervention. Angiology. 2013;64(6):430-434.

13. Miravitlles M, Soriano JB, García-Río F, et al. Prevalence of COPD in Spain: impact of undiagnosed COPD on quality of life and daily life activities. Thorax. 2009;64(10):863-868.

14. Llordés M, Jaén A, Almagro P, et al. Prevalence, risk factors and diagnostic accuracy of COPD among smokers in primary care. COPD. Epub 2014 Dec 4.

15. Soriano JB, Rigo F, Guerrero D, et al. High prevalence of undiagnosed airflow limitation in patients with cardiovascular disease. Chest. 2010; 137(2):333-340.

16. Roques F, Michel P, Goldstone AR, Nashef SA. The logistic EuroSCORE. Eur Heart J. 2003;24(9):881-882.

17. Coluccia V, Burzotta F, Romagnoli E, et al. EuroSCORE predicts long-term mortality of unselected patients undergoing percutaneous coronary interventions. Int J Cardiol. 2013;167(4):1232-1236.

18. Fox KA, Eagle KA, Gore JM, Steg PG, Anderson FA; GRACE and GRACE2 Investigators. The Global Registry of Acute Coronary Events, 1999 to 2009 - GRACE. Heart. 2010;96(14):1095-1101.

19. Sianos G, Morel MA, Kappetein AP, et al. The SYNTAX Score: an angiographic tool grading the complexity of coronary artery disease. EuroIntervention. 2005;1(2):219-227.

20. Farooq V, Brugaletta S, Serruys PW. Contemporary and evolving risk scoring algorithms for percutaneous coronary intervention. Heart. 2011; 97(23): 1902-1913.

21. Khattab AA, Hamm CW, Senges J, et al. Prognostic value of the modified American College of Cardiology/American Heart Association lesion morphology classification for clinical outcome after sirolimuseluting stent placement (results of the prospective multicenter German Cypher Registry). Am J Cardiol. 2008;101(4):477-482.

22. Miller MR, Hankinson J, Brusasco V, et al; ATS/ERS Task Force. Standardisation of spirometry. Eur Respir J. 2005;26(2):319-338.

23. Ferris BG. Epidemiology standardization project (AmericanThoracic Society). Am Rev Respir Dis. 1978;118(6 pt 2)(Suppl 1):1-120.

24. Charlson ME, Pompei P, Ales KL, MacKenzie CR. A new method of classifying prognostic comorbidity in longitudinal studies: development and validation. J Chronic Dis. 1987;40(5):373-383.

25. Vestbo J, Hurd SS, Agustí AG, et al. Global strategy for the diagnosis, management, and prevention of chronic obstructive pulmonary disease: GOLD executive summary. Am J Respir Crit Care Med. 2013; 187(4):347-365.

26. Vanfleteren LE, Spruit MA, Groenen M, et al. Clusters of comorbidities based on validated objective measurements and systemic inflammation in patients with chronic obstructive pulmonary disease. Am J Respir Crit Care Med. 2013;187(7):728-735.

27. Curkendall SM, DeLuise C, Jones JK, et al. Cardiovascular disease in patients with chronic obstructive pulmonary disease, Saskatchewan Canada cardiovascular disease in COPD patients. Ann Epidemiol. 2006; 16(1):63-70.

28. Finkelstein J, Cha E, Scharf SM. Chronic obstructive pulmonary disease as an independent risk factor for cardiovascular morbidity. Int J Chron Obstruct Pulmon Dis. 2009;4:337-349.

29. Almagro P, Cabrera FJ, Diez J, et al. Comorbidities and short-term prognosis in patients hospitalized for acute exacerbation of COPD: the EPOC en servicios de medicina interna (ESMI) study. Chest. 2012; 142(5):1126-1133. 
30. Müllerova H, Agusti A, Erqou S, Mapel DW. Cardiovascular comorbidity in COPD: systematic literature review. Chest. 2013;144(4): 1163-1178.

31. Bérard E, Bongard V, Roche N, et al. Undiagnosed airflow limitation in patients at cardiovascular risk. Arch Cardiovasc Dis. 2011;104(12): 619-626.

32. Yin L, Lensmar C, Ingelsson E, Bäck M. Differential association of chronic obstructive pulmonary disease with myocardial infarction and ischemic stroke in a nation-wide cohort. Int J Cardiol. 2014; 173(3):601-603.

33. Mooe T, Stenfors N. The prevalence of COPD in individuals with acute coronary syndrome: a spirometry-based screening study. COPD. Epub 2014 Nov 21.

34. Maddox TM, Stanislawski MA, Grunwald GK, et al. Nonobstructive coronary artery disease and risk of myocardial infarction. JAMA. 2014;312(17):1754-1763.

35. Wald DS, Morris JK, Wald NJ, et al. Randomized trial of preventive angioplasty in myocardial infarction. $N$ Engl J Med. 2013;369(12): 1115-1123.

36. Andell P, Koul S, Martinsson A, et al. Impact of chronic obstructive pulmonary disease on morbidity and mortality after myocardial infarction. Open Heart. 2014;1(1):e000002.

37. Quint JK, Herrett E, Bhaskaran K, et al. Effect of $\beta$ blockers on mortality after myocardial infarction in adults with COPD: population based cohort study of UK electronic healthcare records. BMJ. 2013;347:f6650.

38. Vivodtzev I, Tamisier R, Baguet JP, Borel JC, Levy P, Pépin JL. Arterial stiffness in COPD. Chest. 2014;145(4):861-875.

39. Maclay JD, McAllister DA, Johnston S, et al. Increased platelet activation in patients with stable and acute exacerbation of COPD. Thorax. 2011;66(9):769-774.
40. Patel AR, Kowlessar BS, Donaldson GC, et al. Cardiovascular risk, myocardial injury, and exacerbations of chronic obstructive pulmonary disease. Am J Respir Crit Care Med. 2013;188(9):1091-1099.

41. Donaldson GC, Hurst JR, Smith CJ, Hubbard RB, Wedzicha JA. Increased risk of myocardial infarction and stroke following exacerbation of COPD. Chest. 2010;137(5):1091-1097.

42. Campo G, Pavasini R, Pollina A, Tebaldi M, Ferrari R. On-treatment platelet reactivity in patients with chronic obstructive pulmonary disease undergoing percutaneous coronary intervention. Thorax. 2014;69(1): 80-81.

43. Hole DJ, Watt GC, Davey-Smith G, Hart CL, Gillis CR, Hawthorne VM. Impaired lung function and mortality risk in men and women: findings from the Renfrew and Paisley prospective population study. BMJ. 1996;313(7059):711-715.

44 Mannino DM, Diaz-Guzman E. Interpreting lung function data using $80 \%$ predicted and fixed thresholds identifies patients at increased risk of mortality. Chest. 2012;141(1):73-80.

45. Moran AE, Forouzanfar MH, Roth GA, et al. Temporal trends in ischemic heart disease mortality in 21 world regions, 1980 to 2010 : the Global Burden of Disease 2010 study. Circulation. 2014;129(14): 1483-1492.

46. Hales CA, Kazemi H. Clinical significance of pulmonary function tests. Pulmonary function after uncomplicated myocardial infarction. Chest. 1977;72(3):350-358.

47. Storey RF, Becker RC, Harrington RA, et al. Pulmonary function in patients with acute coronary syndrome treated with ticagrelor or clopidogrel (from the Platelet Inhibition and Patient Outcomes [PLATO] pulmonary function substudy). Am J Cardiol. 2011;108(11):1542-1546.

48. Vestbo J, Anderson J, Brook RD, et al. The study to understand mortality and morbidity in COPD (SUMMIT) study protocol. Eur Respir J. 2013;41(5):1017-1022.
International Journal of COPD

\section{Publish your work in this journal}

The International Journal of COPD is an international, peer-reviewed journal of therapeutics and pharmacology focusing on concise rapid reporting of clinical studies and reviews in COPD. Special focus is given to the pathophysiological processes underlying the disease, intervention programs, patient focused education, and self management protocols.

\section{Dovepress}

This journal is indexed on PubMed Central, MedLine and CAS. The manuscript management system is completely online and includes a very quick and fair peer-review system, which is all easy to use. Visit http://www.dovepress.com/testimonials.php to read real quotes from published authors. 